\title{
CMEARTICLE
}

\section{Clinics in diagnostic imaging (157)}

Marcus Jian Fu Ong${ }^{1}$, MBBS, Yee Lin Tang ${ }^{2}$, MBBS, Cher Heng $\underline{T a n}^{1}$, MBBS, FRCR
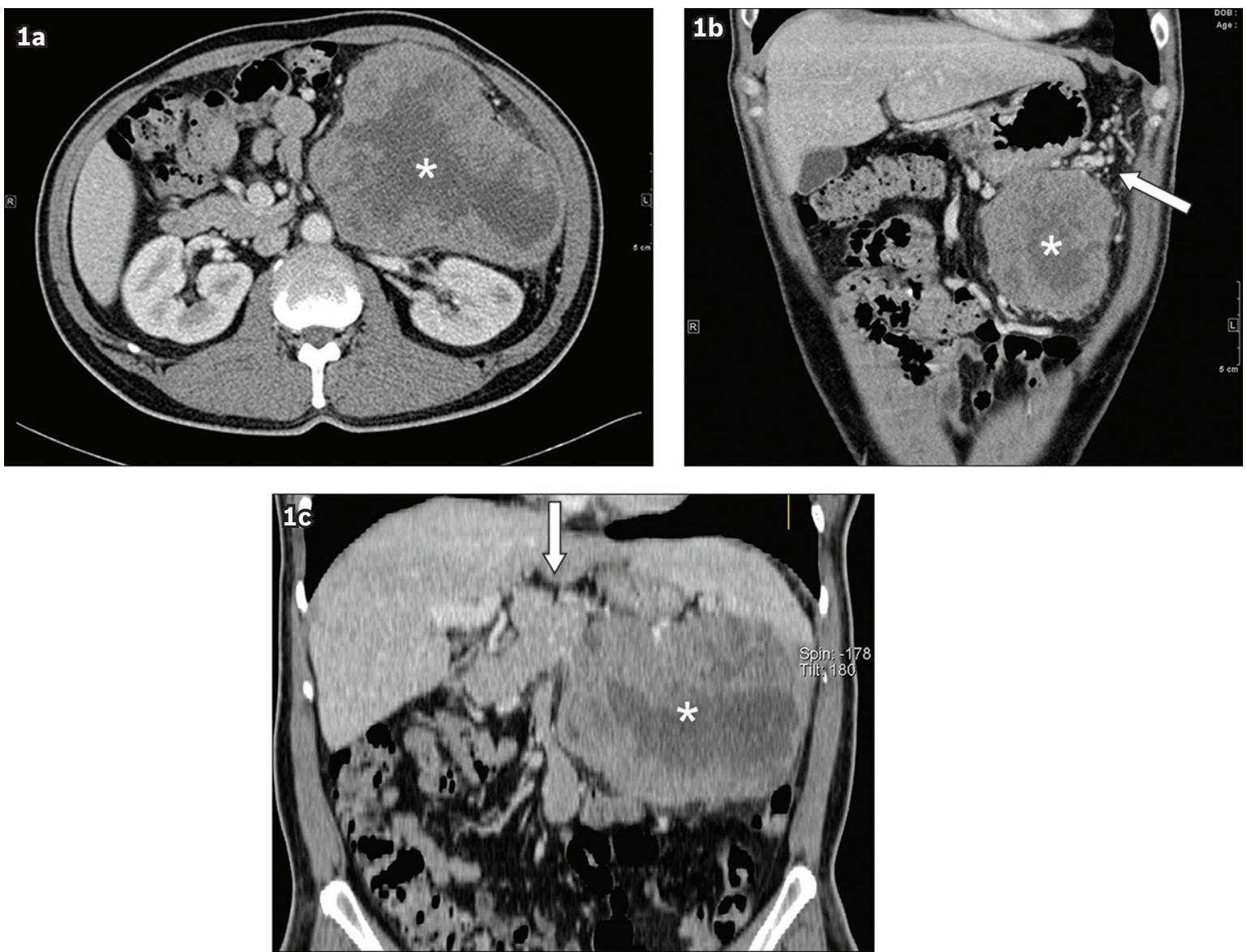

Fig. 1 (a) Axial; (b) coronal reformatted; and (c) multiplanar coronal reformatted contrast-enhanced CT images of the abdomen

\section{CASE PRESENTATION}

A 50-year-old Chinese man presented with pain in the left hypochondrium. This was associated with more than $10 \mathrm{~kg}$ of weight loss in the last three months. Clinical examination revealed a large, firm, ill-defined mass in the left upper quadrant of the abdomen. The patient did not complain of any jaundice, per rectal bleeding or melaena. Tumour markers, including CA 19-9, were found to be normal. Contrast-enhanced computed tomography (CT) of the abdomen and pelvis was performed (Fig. 1). What are the imaging findings? What is the diagnosis?

Department of Diagnostic Radiology, ${ }^{2}$ Department of Pathology, Tan Tock Seng Hospital, Singapore

Correspondence: Dr Ong Jian Fu Marcus, Resident, Department of Diagnostic Radiology, Tan Tock Seng Hospital, 11 Jalan Tan Tock Seng, Singapore 308433. marcus.ong@mohh.com.sg 


\section{IMAGE INTERPRETATION}

Contrast-enhanced CT images of the abdomen reveal a wellcircumscribed left hypochondrial mass with heterogeneous enhancement (indicated by *). The mass is exophytic, with internal areas of necrosis and cystic change (Fig. 1a) seen. The mass also appears to involve the body of the stomach and is closely related to the inferior aspect of the spleen. Dilated vessels (arrow) adjacent to the mass $(*)$ on coronal section (Fig. 1b) are due to external compression of the splenic vein. Multiplanar coronal reformatted images show the mass $(*)$ originating from the pancreas (arrow, Fig. 1c).

\section{DIAGNOSIS}

Acinar cell carcinoma (ACC) of the pancreatic tail.

\section{CLINICAL COURSE}

The patient underwent distal pancreatectomy, splenectomy, en bloc left hemicolectomy and cuff resection of the stomach. Histological findings revealed relatively uniform cuboidal to columnar cells arranged in acini, with extensive glandular formation (Fig. 2). Periodic acid-Schiff stain with diastase (PAS-D) showed eosinophilic granules (Fig. 3). The aforementioned findings confirmed the diagnosis of ACC. The patient was subsequently started on chemotherapy and radiotherapy. Over a one-year postoperative follow-up period, no evidence of local recurrence was detected. The patient continues to be under close surveillance by his oncologist.

\section{DISCUSSION}

ACC is a rare form of exocrine pancreatic tumour. Acinar cells occupy about $80 \%$ of the pancreas, although case studies have reported an incidence of only $0.3 \%-2.0 \%$ of all pancreatic cancers. ${ }^{(1,2)}$ Due to the rarity of ACC, only a small number of case studies have been conducted, thus offering limited insight into the true nature of this malignant condition. Patients with ACC typically present in the sixth decade of life, ${ }^{(1,3)}$ with a clinical presentation that differs from that of pancreatic ductal cell carcinoma, as described by Matos et al. ${ }^{(3)}$ Patients with ACC often complain of abdominal pain $(60 \%)$, back pain $(50 \%)$ and weight loss $(45 \%)$, in contrast with the classical presentation of painless jaundice in pancreatic ductal cell carcinoma. ${ }^{(3)}$

ACC tumours are described as well-circumscribed and exophytic, ${ }^{(4)}$ ranging from solid to cystic, or mixed types. They are usually heterogeneously hypodense with an enhancing capsule. ${ }^{(5)}$ While the location of the tumour is varied, it most commonly occurs in the pancreatic head. ${ }^{(4,6,7)}$ Vascular involvement is seen in $20 \%-33 \%$ of cases, usually of the splenic vein and artery, portal vein, and superior mesenteric vein. The occurrence of lymphadenopathy in ACC is varied. According to Tatli et al, no lymph node involvement was noted in the 11 cases reviewed in their study. ${ }^{(4)}$ Raman et al, however, described lymph node involvement in up to $60 \%$ of patients with peripancreatic lymphadenopathy. ${ }^{(6)}$ Distant metastatic disease was seen in less than $10 \%$ of cases, while biliary and pancreatic ductal dilatation was seen in $14 \%-18 \%$ and $27 \%-28 \%$ of cases, respectively. ${ }^{(4,6)}$

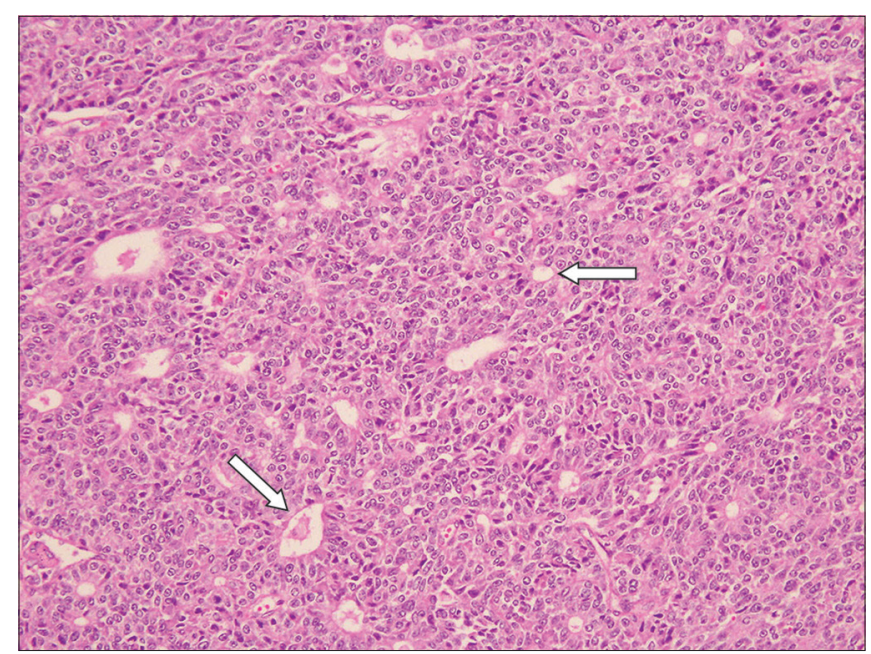

Fig. 2 Photomicrograph shows relatively uniform cuboidal to columnar cells arranged in acini, with extensive glandular formation (arrows), separated by fibrovascular septa. There is minimal intervening stroma between the glands and acini (Haematoxylin \& eosin, × 200).

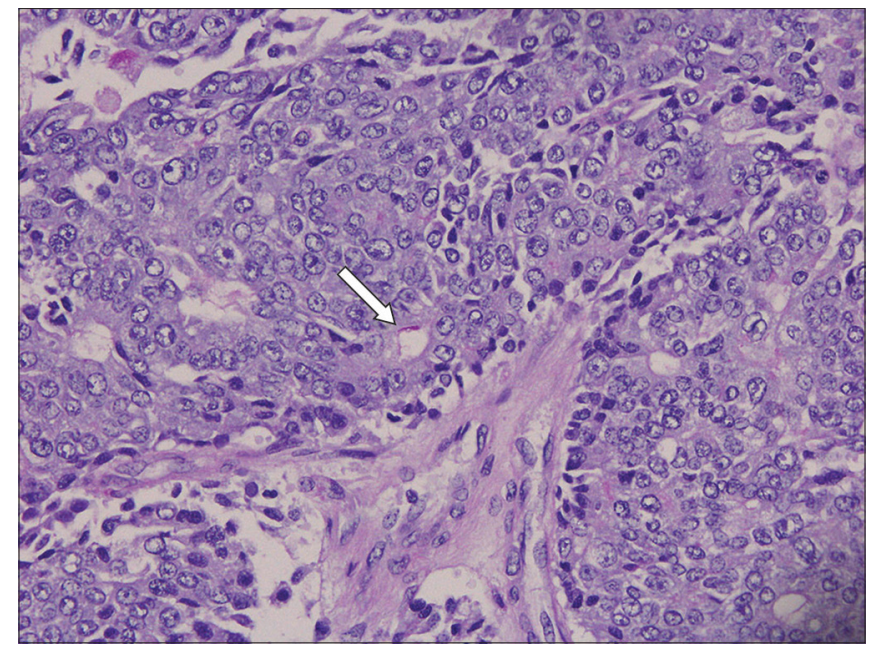

Fig. 3 Photomicrograph shows the presence of eosinophilic granules on the luminal aspect of the cells (arrow) (Periodic acid-Schiff stain with diastase, $\times 400)$.

In our patient, CT images of the abdomen and pelvis revealed a necrotic mass in the pancreatic tail, with heterogeneous enhancement and cystic degeneration. The well-circumscribed exophytic mass involved the body of the stomach and spleen. No nodal or distant metastasis was detected, and no biliary or pancreatic duct dilatation was seen. These findings, together with the radiological features of a well-circumscribed exophytic mass arising from the pancreas, are highly suggestive of a radiological diagnosis of ACC.

The differential diagnosis of a primary pancreatic mass must be considered. The more commonly encountered lesions include pancreatic ductal adenocarcinoma, solid pseudopapillary epithelial neoplasm (SPEN) of the pancreas, and lymphoma.

Pancreatic ductal adenocarcinoma is the most common primary pancreatic malignancy, and should be considered when any solid mass arising from the pancreas, ${ }^{(2)}$ with a typical appearance of a hypoattenuating intraparenchymal mass, is detected. They often present with infiltration into the adjacent 
structures, resulting in pancreatic and biliary ductal dilatation and interruption, with invasion and encasement of the surrounding vessels (Fig. 4). ${ }^{(8)}$ In our patient, the pancreatic mass was exophytic and had minimal features of an invasive tumour. However, the absence of biliary and pancreatic dilatation may not be specific, as adenocarcinomas arising from the pancreatic tail typically do not cause ductal dilatation.

SPEN is a rare pancreatic tumour with low malignant potential that mainly presents in young women. ${ }^{(9)}$ Unlike ACC, SPEN usually presents as a well-encapsulated mass lesion with cystic and haemorrhagic degeneration (Fig. 5). Intermediate and soft tissue attenuation is usually seen peripherally, along with central fluid attenuation. Calcification is often present. The diagnosis of SPEN is less likely in the present case, as our patient did not fit the typical demographic of patients with SPEN. Furthermore, despite its large size, the pancreatic tumour in this present case was predominantly solid, with no typical features of a SPEN tumour demonstrated.

Lymphoma usually presents as a homogeneously attenuating soft tissue mass with minimal enhancement on contrast administration. Due to tumour infiltration, diffuse enlargement of the pancreas may be seen. The primary tumour occasionally arises from the pancreas but more often originates from pancreaticoduodenal lymph nodes, with infiltration of the pancreas (Fig. 6). ${ }^{(10)}$ Similar to ACC, pancreatic duct dilatation in lymphoma is rare. ${ }^{(11)}$ Core biopsy with histological samples should be performed whenever lymphoma is suspected.

Histologically, the most common patterns seen in ACC are acinar, solid, glandular and trabecular formations. Cells typically contain round, relatively monomorphic nuclei, single prominent nucleoli, and moderate amounts of eosinophilic granular cytoplasm. Generally, PAS-D shows granules located in the apical region, although these may be focal, as was seen in our case. ${ }^{(13-16)}$ Immunohistochemical staining for zymogens such as trypsin, lipase and amylase are positive in ACC. ${ }^{(13-16)}$

Kitagami et al found that ACC has a poorer prognosis as compared to ductal cell carcinoma of the pancreas, which the authors attributed largely to the late presentation of ACC cases. ${ }^{(1)}$ Other studies have shown better prognoses in patients with ACC, with superior survival rates. A matched analysis from the Memorial-Sloan Kettering Cancer Center pancreatic cancer database showed that the median survival was eight months in patients with ductal adenocarcinoma as compared to 19 months in patients with ACC.(17) The National Cancer Institute's SEER programme also quoted five-year survival rates of $2.3 \%$ for ductal cell adenocarcinoma of the pancreas versus $28.3 \%$ for ACC. ${ }^{(2)}$

Surgery remains the definitive treatment for ACC (in cases of resectable tumours), and involves pancreaticoduodenectomy or distal pancreatectomy. Radiotherapy has some effect on unresectable tumours, but chemotherapy has thus far proven disappointing. Seth et al found that the median survival of postoperative patients was 33 months, while the one- and fiveyear survival rates were $75 \%$ and $37 \%$, respectively. ${ }^{(12)}$ Another study reported one- and five-year survival rates of $92 \%$ and $53 \%$,

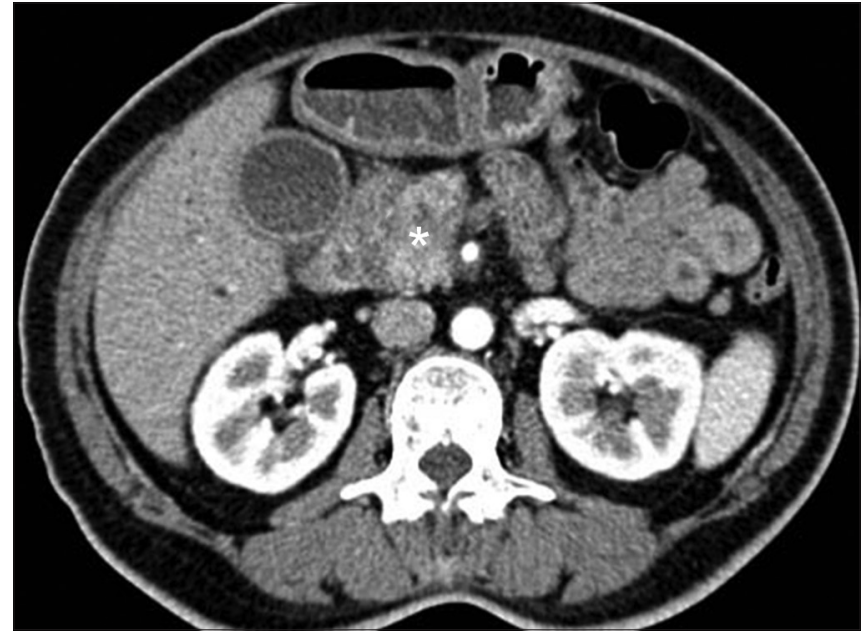

Fig. 4 Pancreatic ductal adenocarcinoma in a 62-year-old man with obstructive jaundice. Contrast-enhanced axial CT image of the abdomen shows a speculated, infiltrative pancreatic head ductal adenocarcinoma $\left({ }^{*}\right)$ with encasement of the superior mesenteric artery. The patient underwent a Whipple procedure and adjuvant chemotherapy, but passed away two years later.

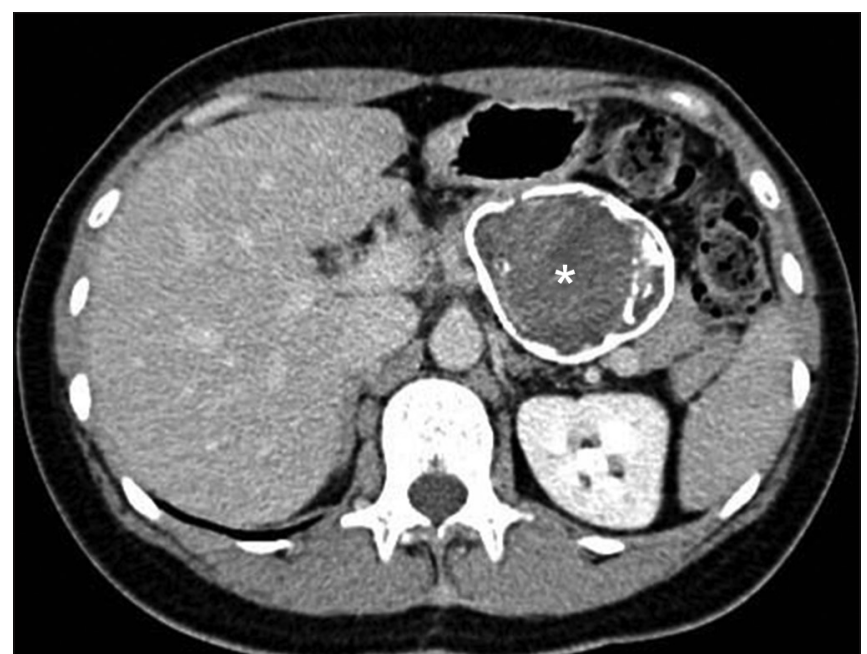

Fig. 5 Solid pseudopapillary epithelial neoplasm in a 42-year-old woman with back pain. Contrast-enhanced axial CT image of the abdomen shows a well-encapsulated pancreatic mass with cystic-haemorrhagic degeneration and areas of calcification $\left(^{*}\right)$. The diagnosis was histologically proven. The patient underwent a distal pancreatectomy and is now in remission.

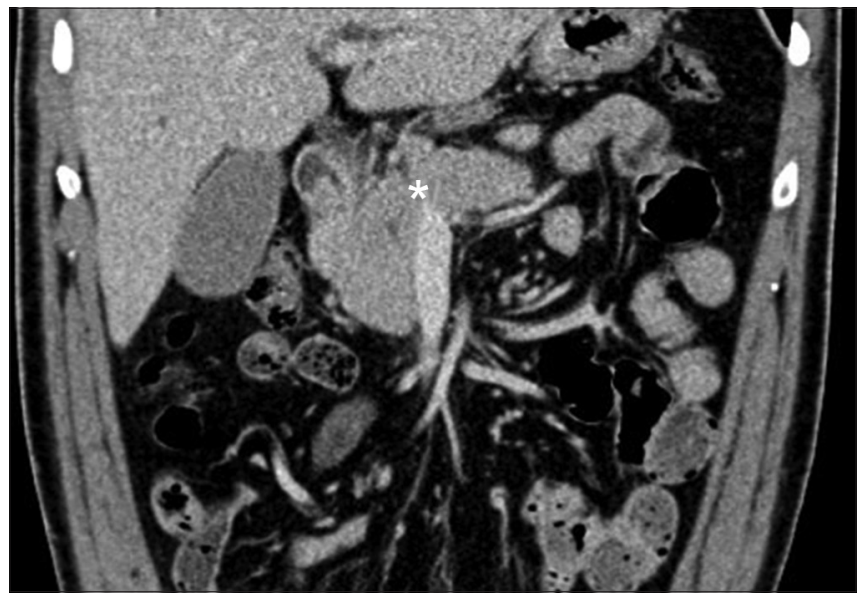

Fig. 6 Lymphoma in a 32-year-old man with abdominal pain and jaundice. Contrast-enhanced coronal CT image of the abdomen shows lymphoma with diffuse infiltration of the pancreas $\left(^{*}\right)$. The patient underwent a Whipple procedure and chemotherapy, and is currently in remission and on surveillance. 
respectively, in postoperative patients with $\mathrm{ACC} .{ }^{(3)}$ In a large study comprising 115 patients with ACC who had been registered in the Japan Pancreas Society Pancreatic Cancer Registry over a period of more than 23 years, Kitagami et al ${ }^{(1)}$ found that surgical resection allowed for improved survival outcomes. The five-year survival rate was noted to be $43.9 \%$, with a median survival time of 41 months, while the five-year survival for patients with unresectable tumours was a dismal $0 \%$, with a median survival time of three months. ${ }^{(1)}$

In summary, the CT findings of ACC are typically described as well-circumscribed exophytic pancreatic masses. These masses are also seen to have a lower propensity for vascular invasion and distant metastases as compared to the more common pancreatic adenocarcinoma. Better survival rates are seen in patients with ACC as compared to those with ductal cell carcinoma of the pancreas. With implications on pre-treatment planning, ACC is an important consideration in patients presenting with predominantly solid, exophytic primary pancreatic tumours.

ABSTRACT A 50-year-old Chinese man presented to the clinic with left hypochondrial pain, more than $10 \mathrm{~kg}$ of weight loss over a 3-month period, and a firm, large, ill-defined mass in the left upper quadrant. Contrastenhanced computed tomography of the abdomen and pelvis revealed a well-circumscribed exophytic pancreatic mass with features suggestive of acinar cell carcinoma (ACC). The patient underwent chemotherapy and radiotherapy, with no evidence of local recurrence detected at one-year follow-up. He remains under close surveillance by his oncologist. Treatment for ACC includes surgical resection with adjuvant radiotherapy. Better overall survival is seen in patients with surgically resectable ACC as compared to those with the more common ductal cell carcinoma.

Keywords: acinar cell carcinoma, cancer, computed tomography, pancreas

\section{REFERENCES}

1. Kitagami H, Kondo S, Hirano S, et al. Acinar cell carcinoma of the pancreas: clinical analysis of 115 patients from Pancreatic Cancer Registry of Japan Pancreas Society. Pancreas 2007; 35:42-6.

2. Key C. Cancer of the pancreas. In: Bethesda MD. National Cancer Institute. SEER Survival Monograph: Cancer Survival Among Adults: US SEER Program, 1988-2001, Patient and Tumor Characteristics. Publication no.: NIH-07-6215

3. Matos JM, Schmidt CM, Turrini O, et al. Pancreatic acinar cell carcinoma: a multi-institutional study. J Gastrointest Surg 2009; 13:1495-502.

4. Tatli S, Mortele KJ, Levy AD, et al. CT and MRI features of pure acinar cell carcinoma of the pancreas in adults. AJR Am J Roentgenol 2005; 184:511-9.

5. Chiou YY, Chiang JH, Hwang Jl, et al. Acinar cell carcinoma of the pancreas: clinical and computed tomography manifestations. J Comput Assist Tomogr 2004; 28:180-6.

6. Raman SP, Hruban RH, Cameron JL, et al. Acinar cell carcinoma of the pancreas: computed tomography features--a study of 15 patients. Abdom Imaging 2013; 38:137-43.

7. Bhosale $\mathrm{P}$, Balachandran A, Wang $\mathrm{H}$, et al. CT imaging features of acinar cell carcinoma and its hepatic metastases. Abdom Imaging 2012; 38:1383-90.

8. Ahn SS, Kim MJ, Choi JY, et al. Indicative findings of pancreatic cancer in prediagnostic CT. Eur Radiol 2009; 19:2448-55.

9. Buetow PC, Buck JL, Pantongrag-Brown L, et al. Solid and papillary epithelial neoplasm of the pancreas: imaging-pathologic correlation on 56 cases. Radiology 1996; 199:707-11.

10. Fishman EK, Kuhlman JE, Jones RJ. CT of lymphoma: spectrum of disease. Radiographics 1991; 11:647-69.

11. Lee WK, Lau EW, Duddalwar VA, Stanley AJ, Ho YY. Abdominal manifestations of extranodal lymphoma: spectrum of imaging findings. AJR Am J Roentgenol 2008; 191:198-206.

12. Seth AK, Argani P, Campbell KA, et al. Acinar cell carcinoma of the pancreas: an institutional series of resected patients and review of the current literature. J Gastrointest Surg 2008; 12:1061-7.

13. Klimstra DS, Heffess CS, Oertel JE, Rosai J. Acinar cell carcinoma of the pancreas. A clinicopathologic study of 28 cases. Am J Surg Pathol 1992; 16:815-37.

14. Klimstra DS. Nonductal neoplasms of the pancreas. Mod Pathol 2007; 20 suppl 1:S94-112.

15. Klimstra DS, Hurban RH, Kloppel G. Acinar cell neoplasm of the pancreas. In: Bosman FT, Carnerio F, Hruban RH, Theise ND, eds. WHO Classification of Tumours of the Digestive System. Lyon: IARC, 2010: 314-8.

16. La Rosa S, Adsay V, Albarello L, et al. Clinicopathologic study of 62 acinar cell carcinomas of the pancreas: insights into the morphology and immunophenotype and search for prognostic markers. Am J Surg Pathol 2012; 36:1782-95.

17. Holen KD, Klimstra DS, Hummer A, et al. Clinical characteristics and outcomes from an institutional series of acinar cell carcinoma of the pancreas and related tumors. J Clin Oncol 2002; 20:4673-8. 


\section{SINGAPORE MEDICAL COUNCIL CATEGORY 3B CME PROGRAMME} (Code SMJ 201411B)

Question 1. Regarding acinar cell carcinoma:

(a) It has an incidence of about $0.3 \%-2.0 \%$ of all pancreatic cancers.

(b) It arises from the endocrine glands of the pancreas.

(c) Eosinophilic granules are seen with periodic acid-Schiff stain with diastase.

(d) It most commonly presents with abdominal pain.

Question 2. Regarding treatment and outcome of acinar cell carcinoma:

(a) Surgery is the definitive treatment.

(b) Chemotherapy is a well-proven adjunctive treatment.

(c) Radiotherapy is not helpful.

(d) It has better survival rates than ductal adenocarcinoma of the pancreas.

Question 3. Are the following statements true or false?

(a) Acinar cell carcinoma may be solid or cystic.

(b) Solid pseudopapillary endothelial neoplasms (SPEN) usually has cystic-haemorrhagic degeneration with calcification.

(c) SPEN usually occurs in male patients.

(d) SPEN has low malignant potential.

Question 4. Are the following statements true or false?

(a) Acinar cell carcinoma does not present with lymphadenopathy.

(b) Primary pancreatic lymphoma is common.

(c) Lymphoma usually involves lymphadenopathy with infiltration of the pancreas.

(d) Tumours in ductal adenocarcinoma of the pancreas are usually infiltrative.

Question 5. Are the following statements true or false?

(a) Ductal dilatation is uncommon in ductal adenocarcinoma of the pancreas.

(b) Pancreatic ductal adenocarcinoma commonly occurs after 60 years of age.

(c) Adenocarcinoma of the pancreas has a five-year survival time.

(d) Metastasis is common at the time of presentation of pancreatic ductal adenocarcinoma.

True

False

$\square$

$\square$

$\square$

\section{Doctor's particulars:}

Name in full

MCR number

Email address

Specialty:

\section{SUBMISSION INSTRUCTIONS:}

(1) Log on at the SMJ website: http://www.sma.org.sg/publications/smjcurrentissue.aspx and select the appropriate set of questions. (2) Provide your name, email address and MCR number. (3) Select your answers and click "Submit".

\section{RESULTS:}

(1) Answers will be published in the SMJ January 2015 issue. (2) The MCR numbers of successful candidates will be posted online at the SMJ website by 2 January 2015. (3) Passing mark is $60 \%$. No mark will be deducted for incorrect answers. (4) The SMJ editorial office will submit the list of successful candidates to the Singapore Medical Council. (5) One CME point is awarded for successful candidates.

Deadline for submission: (November 2014 SMJ 3B CME programme): 12 noon, 26 December 2014. 